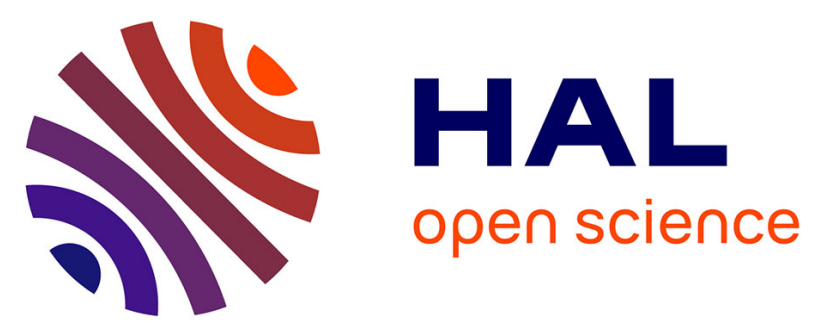

\title{
On the Use of Thermal Images for Circulation Studies: Applications to the Eastern Mediterranean Basin
}

\author{
Isabelle Taupier-Letage
}

\section{To cite this version:}

Isabelle Taupier-Letage. On the Use of Thermal Images for Circulation Studies: Applications to the Eastern Mediterranean Basin. Vittorio Barale; Martin Gade. Remote Sensing of the European Seas, Springer, pp.153-164, 2008, Remote Sensing of the European Seas, 978-1-4020-6772-3. 10.1007/9781-4020-6772-3_12. hal-01196705

\section{HAL Id: hal-01196705 \\ https://hal.science/hal-01196705}

Submitted on 10 Sep 2015

HAL is a multi-disciplinary open access archive for the deposit and dissemination of scientific research documents, whether they are published or not. The documents may come from teaching and research institutions in France or abroad, or from public or private research centers.
L'archive ouverte pluridisciplinaire HAL, est destinée au dépôt et à la diffusion de documents scientifiques de niveau recherche, publiés ou non, émanant des établissements d'enseignement et de recherche français ou étrangers, des laboratoires publics ou privés. 


\title{
The use of thermal images for circulation studies: application to the eastern basin of the Mediterranean
}

\author{
Isabelle Taupier-Letage isabelle.taupier-letage@univ-amu.fr \\ Centre National de la Recherche Scientifique et Université de la Médite r- \\ ranée, Laboratoire d'Océanographie et Biogéochimie, Antenne de Toulon, \\ BP 330, 83507 La Seyne/Mer, France
}

\begin{abstract}
The use of satellite thermal infrared images to infer marine circulation features is presented, here in the case of the eastern basin of the Mediterranean. Indeed, although the first schema of the surface circulation (water of Atlantic origin: $\mathrm{AW}$ ) in the Mediterranean is one century old, the path of AW in the Eastern Basin is still debated nowadays. Does it flow along the Libyan and Egyptian slopes in a counterclockwise circuit at basin scale, or as an offshore jet that crosses the basin in its central part ("Mid-Mediterranean Jet")? In this paper we describe the use and contribution of the thermal images for the study of the surface circulation in the Eastern Basin, currently underway within the framework of the programs EGYPT (Eddies and GYres Paths Tracking) and EGITTO (2005-2008).
\end{abstract}

\section{Introduction}

The water lost by evaporation in the Mediterranean is compensated by light Atlantic Water (AW). AW flows over the saltier -thus denser- Mediterranean waters (MWs), and determines the surface circulation (for a review of the general circulation in the Mediterranean see Millot and Taupier-Letage (2005a) and references therein). Overall, and due to the earth rotation, AW and MWs are expected to follow the bathymetry and describe quasi-permanent counterclockwise circuits, in both the western and the eastern basins. The first schema of the surface circulation dates back to the early 1910s: it showed counterclockwise circuits in both basins (see Fig.1a). In the 1990s, the experiment Physical Oceanography of the Eastern Mediterranean (POEM) issued a schema (Fig. 1b) depicting the AW path as an offshore jet, crossing the basin in its central part (the socalled "Mid-Mediterranean Jet": MMJ), and feeding mesoscale circulations on both sides (Robinson et al. 1991). That latter representation has 
been questioned (Millot, 1992). Firstly because satellite thermal images display features analogous in both basins (Fig. 2), and secondly because no in situ observations were available in the southernmost part of the Eastern Basin. The thermal signature of AW (warmer in winter; Fig. 2a) can be tracked along the southern continental slopes of both basins. In both basins too the flow of AW in the South forms currents that are unstable at mesoscale (Fig. 2c-f). They meander and generate anticyclonic eddies that often extend down to the bottom and have lifetimes of several months. Eddies propagate usually downstream or in the basins interior at a few $\mathrm{km}$ per day, and are thus likely to interact with their parent current or other eddies.

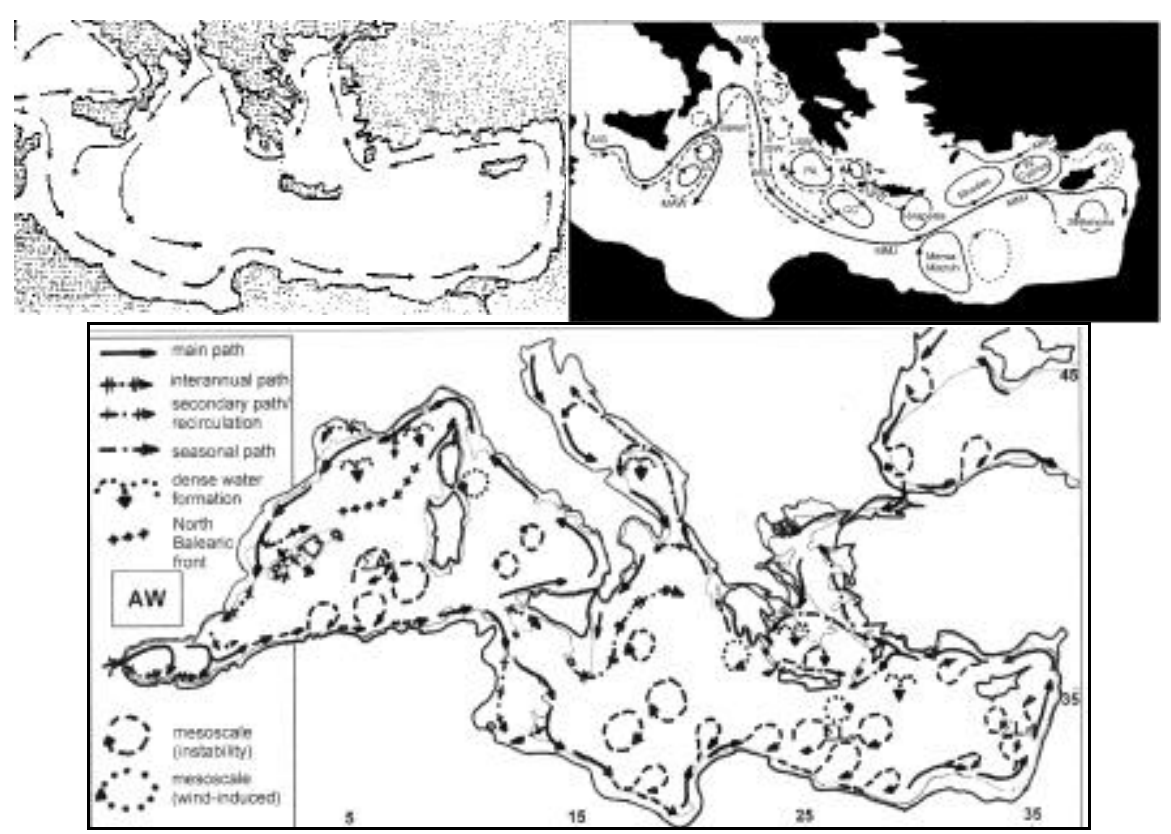

Fig. 1 The schema of the surface circulation according to: $a$ ) Nielsen (1912); $b$ ) Robinson et al. (1991); c) Millot and Taupier-Letage (2005a)

This intense mesoscale activity induces a very high variability in both space and time, which impairs interpreting the observations that do not resolve mesoscale properly. By combining thermal (mainly) satellite images and in situ observations, Millot et al (1997) and Taupier-Letage et al (2003) showed the role of such mesoscale eddies in entraining AW and MWs from the periphery towards the central part of the basins, and thus in diverting potentially (part of) the flow from its expected path. This allowed solving a similar controversy about the path of the Levantine Intermediate Water in the southern part of the Western Basin (Millot and Taupier- 
Letage, 2005b). Hamad et al (2005) have analysed a 4year time series of thermal images covering the Eastern Basin, and confronted the in situ observations (among which the POEM data and repeated XBT transects) with their thermal signatures. They observed a permanent eastward circulation in the south, that they named the Libyo-Egyptian Current (Fig. 1c, Fig. 2f). Zervakis et al (2003) and Fusco et al (2003) also concluded that there was a permanent coastal flow (the MMJ in the latter case, $c f$ their Fig. 10). Given the presence of coastal libyo-egyptian eddies at the time of POEM, Hamad et al $(2005,2006)$ suggested $i)$ that these eddies were responsible for spreading the AW found offshore, and $i$ ) that the meandering MMJ was a misinterpretation of the AW found on the northern edges of successive eddies. The joint programs EGYPT ${ }^{1}$ (Eddies and GYres Paths Tracking) and EGITTO ${ }^{2}$ are currently (2005-2008) collecting in situ observations to study the circulation in the Eastern Basin, with focus on its southernmost part. The methodology to infer circulation features from the thermal imagery is described in section 2 . The first results of the confrontation between in situ and satellite observations are described in section 3 and discussed in section 4 , together with the conclusion.

\section{Methodology to infer circulation features from thermal imagery}

The retrieval of the sea surface temperature (SST) from remote sensing in the thermal infrared is routine work. The detailed principles are beyond the scope of this paper; therefore the reader is referred to other chapters of this book or for instance to the site of the Medspiration ${ }^{3}$ project.

\subsection{The eligible products and selection criteria}

The most adequate products to track (mesoscale) circulation features are infrared thermal images derived from the AVHRR (Advanced Very High Resolution Radiometer) sensor. The temporal coverage is ensured by two (at least) satellites flying simultaneously and providing at least $4 \mathrm{~m}$ ages/day over the Mediterranean, the synoptic view by a swath $>2000 \mathrm{~km}$, the spatial resolution by a pixel of $\sim 1 \mathrm{~km}$, and the detection of the features by a $\sim 0.12^{\circ} \mathrm{C}$ thermal resolution (Fig. $2-5$ ). The typical processing includes

\footnotetext{
${ }^{1}$ http://www.ifremer.fr/EGYPT

${ }^{2}$ http://doga.ogs.trieste.it/sire/drifter/egitto main.html

${ }^{3}$ http://www.medspiration.org/science
} 
the retrieval of the SST from the combination of 2 to 3 infrared channels, the geographical registration, with possibly the generation of cloud and land masks. Images can be then composed into daily to monthly products. SST images are routinely generated and made available on numerous data centers for free.

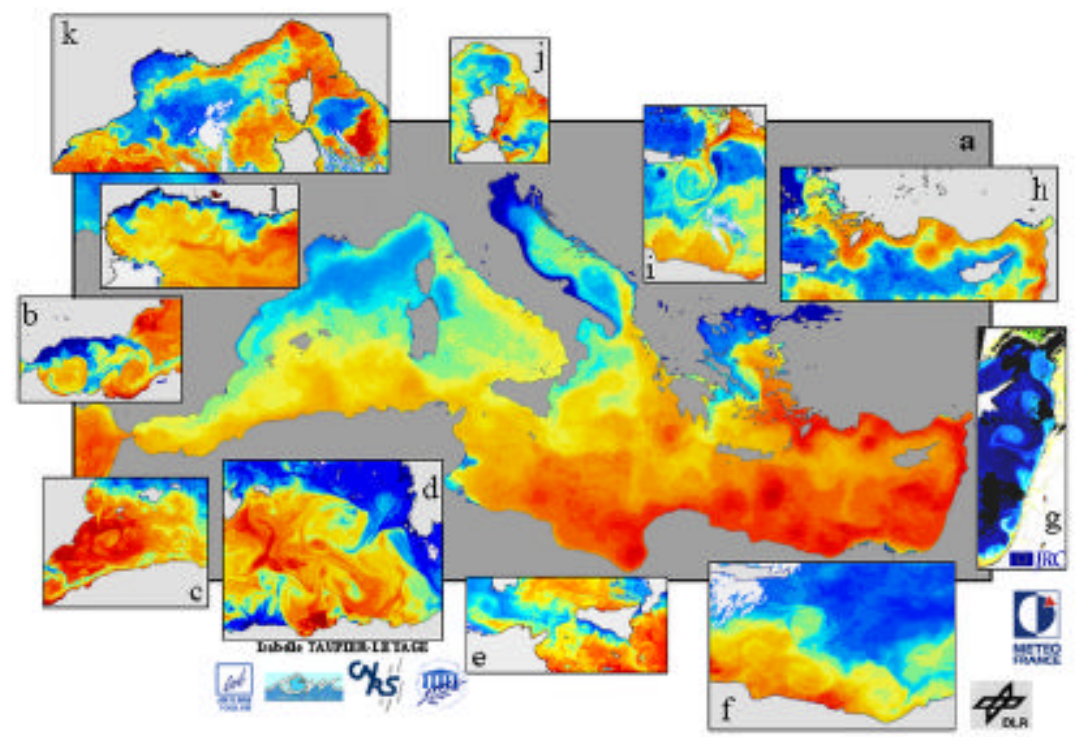

Fig. 2 The surface circulation in the Mediterranean seen with thermal images. a): Atlantic Water (warmer) can be tracked all around the continental slopes in a counterclockwise circuit; $b-l)$ : the mesoscale dynamics and associated variability. Temperature increases from blue to red. $a, h$ ): monthly SST composite for January 1998 (from DLR); $(b-f$ and $i-l)$ : single passes. $g$ ): ocean colour from SeaWiFS (from JRC/Ispra)

Although the circulation features can be detected from SST images (see Fig. 2a, h and Fig. 4f-g), a tailored product has been determined and generated $^{4}$ to meet the needs for a fine resolution in both space $(1 \mathrm{~km})$ and time (single pass, every day) and for near-real time availability, as required to sample mesoscale features (that may be propagating) in situ. This product is the image of the channel $\$$ (brightness temperatures, hereafter called thermal image). The image is extracted from of a single pass, at a $1-\mathrm{km}$ resolution, and geographically registered. The size of the file is decreased by recoding the image over 8 bits (10 bits originally); the original thermal

${ }^{4}$ By the SATMOS/INSU-Méteo France facility http://www.satmos.meteo.fr/), and used throughout this paper unless otherwise stated.

5 A single channel is preferred for delineating features since the multi-channel combination increases the noise in the SST image. 
dynamics is preserved by keeping only the numerical counts that correspond to marine temperatures (usually from 5 to $32^{\circ} \mathrm{C}$ ). To decrease the size further the land is masked, the larger clouds too (flagged by a simple threshold, usually temperatures $<5^{\circ} \mathrm{C}$ ), and the file is compacted with a lossless algorithm. If the file is an image a grayscale is used to preserve the possibility to adjust the contrast specifically. The generation of such products is fully automated, cheap, and easily completed within one hour after the satellite pass.

The infrared signal only comes from the upper few microns (the "skin" temperature; see e.g. Nardelli et al. 2005 for more details). Therefore the thermal signatures cannot be, a priori, related to the dynamics of the

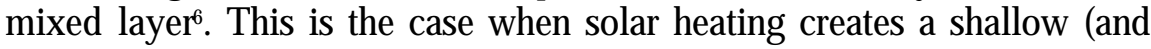
temporary) thermocline, which caps the thermal patterns of the mixed layer. Nighttime passes are thus preferred. On the other hand the wind blows very often and mixes the upper layer, so that the surface temperature is representative of that of the mixed layer?

\subsection{The link between thermal signature and ocean dynamics}

In the Mediterranean, the surface circulation can be tracked most generally by tracking the higher temperatures, which correspond to the lower salinity -and thus lighter- $\mathrm{AW}^{8}$. Such conditions are optimum in winter, as seen on Figure 2a. Note that this is also true independently of the latitude, as shown by the $\mathrm{AW}$ warmer current flowing along the northernmost parts of both basins on Figure 2a, $\mathrm{h}$ and $\mathrm{k}$.

The tracking of the mesoscale features from their thermal signature relies on the fact that there must be coherence between the temporal and the spatial scales. Indeed, the infrared signature of a shallow phenomenon will have a transient lifetime, of the order of hour(s) or day(s). This is the case for diurnal heating or some wind-induced phenomena. Conversely, the thermal signature that can be tracked for months -up to years- necessarily corresponds to a structure having a deep vertical extent, a condition required to maintain the signature over time, especially to survive winter mixing (see e.g. the 3-year tracking of algerian eddies by Puillat et al (2002), and of libyo-egyptian eddies by Hamad et al (2006)). But there is

\footnotetext{
${ }^{6}$ Ocean colour images are better since the signal comes from a thicker layer. But their processing is no real routine, and the temporal coverage is much less.

${ }^{7}$ Possibly even under summertime conditions at noontime, as shown by Fig. 4a: the northerly winds mix and cool the surface layer on both sides of Crete, clearly revealing anticyclones.

${ }^{8}$ Isopycnals and isotherms mostly co-vary.
} 
no direct relation between the intensity (i.e. the thermal gradient) of a signature and the intensity of the structure itself (vertical extent or current speed). For instance a cyclonic eddy is associated with a doming of the isopycnals, so that deeper/colder water intersect the surface in the centre and delimit an intense thermal gradient: the resulting small cold spots will always be detected (Fig. 2d; 3i). However such cyclonic eddies ${ }^{9}$ are known to be shallow and transient. Conversely, an anticyclonic eddy is associated with a depression of the isopycnals, and its generic signature is a warmer (lighter water) central area. While this is always verified during wintertime because of mixing (e.g. Fig.3b-c, Fig. 5b), under stratified conditions the isotherms may not intersect the surface, and hence anticyclones may not exhibit any intrinsic signature. They are detected then indirectly by the superficial water they entrain, up to displaying a colder central area. The resulting variability of an eddy's signature is illustrated by the figures 3 and $4^{10}$. Finally, the temperature difference between AW and MW reverses on a yearly cycle: spring and fall are thus less favourable periods for tracking thermal patterns, and even a difference of $\sim 0.1^{\circ} \mathrm{C}$ (thermal resolution) can sometimes delimit a structure and thus be significant (see eddy $(\Delta)$ onFig.3d).

Most often the current is parallel to the isotherms, and generally the inference of the currents is intuitive. One image allows deducing the current direction associated with the eddies, since the isotherms always spiral inside. One can estimate their diameter and centre location, even from segments of isotherms on images partially cloud-covered (Fig. 3a, k). But since the eddy's signature may vary according to the water its entrains, estimates of its size can hardly be precise, but in winter when the mixed layer is thick. Time series of images allow deducing the trajectory and the propagation speed from the successive positions of the features (isotherms are then perpendicular to the propagation direction).

During cloudy periods the dynamical features can be tracked using the anomaly they generate on the sea level with altimetric tracks (e.g. Pujol and Larnicol 2005), and/or using composite thermal images. But care must be taken when using interpolated or composite images that the longer the time span the smoother the signature of a propagating structure, up to potentially yielding a misleading picture. hdeed, where successive eddies propagating along the coast mainly induce cross-shore gradients (cf Fig. $2 \mathrm{~d}$, f), the image resulting from a long-time average will display a smooth band parallel to the coast, with gradients mainly oriented along-shore.

\footnotetext{
${ }^{9}$ Cyclonic eddies are secondary phenomena, induced by the shear.

${ }^{10}$ Symmetrically, two cyclonic shear eddies display a warmer signature on Fig. $2 \mathrm{~d}$
} 


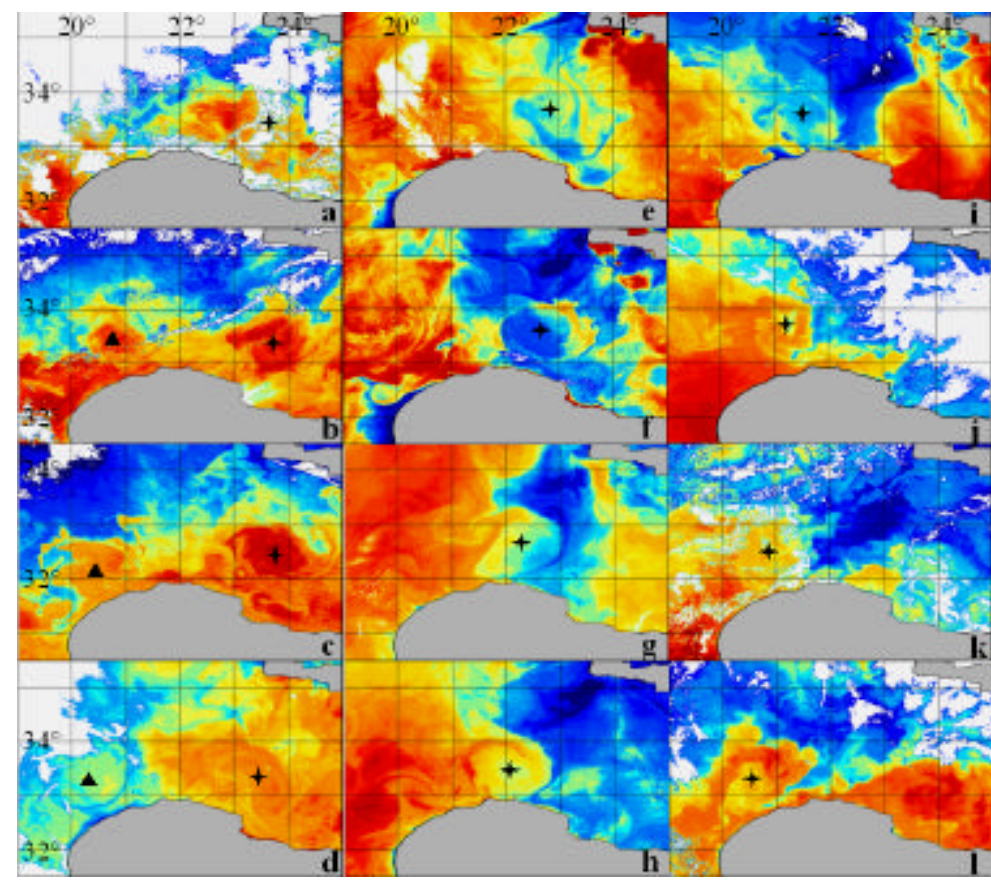

Fig. 3 Time series used to track the libyan eddy (+) during 2006: $a$ ) 08 Jan.; $b$ ) 10 Feb.; c) 06 Mar.; d) 26 Apr.; e) 28 May;f) 17 Jun.; g) 23 Jul.; h) 18 Aug.; i) 14 Sep.;j) 26 Oct.; $k) 08$ Nov.; l) 19 Dec. 2006. $\Delta$ : an other libyan eddy

\subsection{The interpretation of the thermal signatures}

The first step is to discriminate between oceanic and atmospheric signatures. This is relatively easy because both types of phenomena have different space and time scales. Clouds are changing and moving more rapidly than any oceanic phenomena, so that comparing two images prevents from mistaking the limits of a cloud or haze for those of an eddy. Patterns too are characteristic: isotherms associated with oceanic phenomena are smoother and less patchy, and are mostly tangential: one should suspect atmospheric contamination wherever isotherms intersect.

The second step is to detect and evidence the circulation features. As shown above the temperature is not a sufficient criterion, as its value and the gradient it determines vary with its environment, the season, the meteorological conditions and the time of day. This requires stretching the colour scale to adjust the contrast for each image, sometimes even differently for the same image to evidence circulation features at the Mediterranean (Fig. 2a) and sub-basin (Fig. 2h) scales. If the retrieval of accurate tem- 
perature (SST) is crucial for climatological studies, it is not an issue for process studies so that colour-temperature scales are not relevant.

The third step is to check whether the thermal signature corresponds to an actual dynamical structure. Its presence and lifetime must be verified on several images, possibly using other satellite information too (e.g. visible/ocean colour imagery, or altimetry to establish the continuity during cloudy periods).

The final step is to characterize the circulation features: one considers the shape, location and consistency of isotherms. The most common analysis consists in reporting the isotherms (possibly segments only) delineating a circulation feature, and in superimposing its successive signatures (as illustrated by the figure 3 of Marullo et al 2003). The recurrence of contours ends up in delineating the whole feature, its centre in the case of an eddy, and, should it move, its direction and propagation speed.

\section{New results on the circulation in the Eastern Basin}

The EGYPT and EGITTO experiments provide a new insight in the surface circulation. The confrontation of concurrent in situ with remotely sensed observations is focused here on the year 2006. Note that the data sets analysis is currently underway and related paper still in preparation ${ }^{11}$.

\subsection{A newly observed drift for libyan eddies}

From the previous study spanning 4 years, eddies along the Libyan slope had only been observed drifting eastward (Hamad et al. 2006). The figure 3 (d-1) shows 2 libyan eddies drifting westward: one (+) from April during 9 months at least (detailed tracking interrupted after December 2006), the other one upstream ( $\Delta$ ) during 3 months at least (no specific tracking).

\subsection{Few-days temporal variability: the merging of eddies}

The northerly winds (Etesians) blowing during summertime generate eddies. The anticyclone induced Southwest of Crete is called Ierapetra. Several authors have reported its persistence after the decay of the Etesians, and the fates of successive generations of Ierapetra are described in

\footnotetext{
${ }^{11}$ References of papers will be available on the EGYPT and EGITTO web sites.
} 
Hamad et al (2006). The situation of summertime 2006 is detailed in figure 4. In May the Ierapetra generated in summer $2005(\mathrm{I} 05$, o) appears as a large anticyclone. By 5 July the signature of Ierapetra $2006(\mathrm{I} 06,+)$ is definitely established, and both signatures co-exist. The size of I06 doubles in 5 days, and by 19 July I06 is larger than I05. I06 moves to the South and begins interacting strongly with I05: their merging takes less than 4 days, and by 23 July there is only one anticyclone signature. So that by 27 July (Fig. 4j) the situation appears similar to that of late May (Fig. 4a), but the Ierapetra eddy is different.

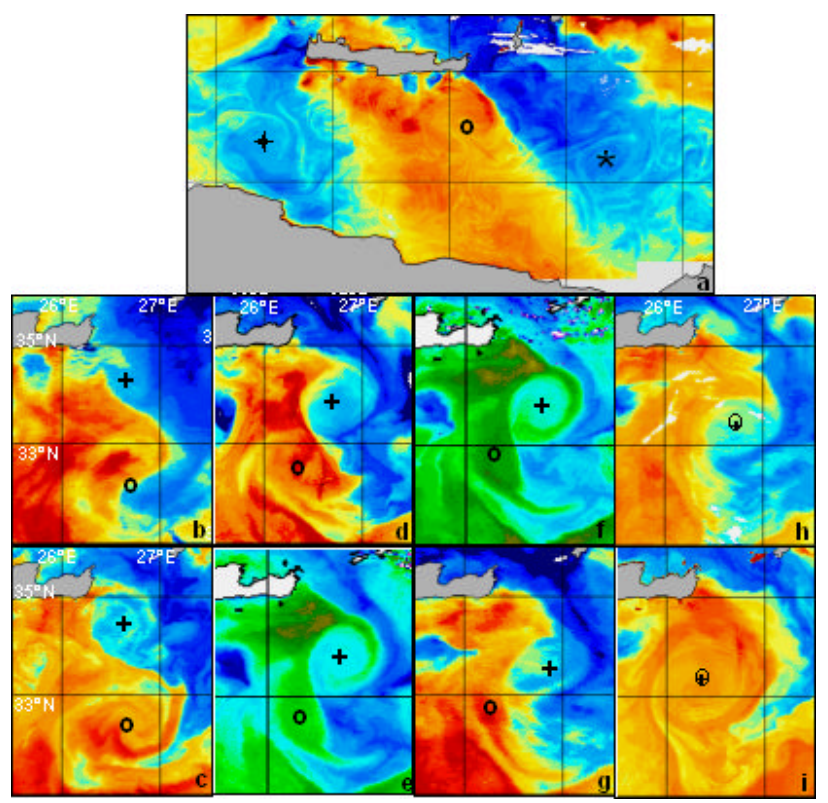

Fig. 4 Summer 2006: the merging of the Ierapetra eddies created respectively in 2005 (I05: o) and $2006($ I06: +) : a) situation on 28 May 11:59; b) 05 Jul. 20:52 ; c) 10 Jul. 20:38; d) 16 Jul. 00:29; e) 19 Jul. 20:31; f) 20 Jul. 23:42; g) 21 Jul. 04:25, h) 22 Jul. 01:07; i) 23 Jul. 20:39; j) 27 Jul. 11:48 2006. $f$ and $g$ : SST from CYCOFOS 12

\subsection{The sampling strategy dedicated to mesoscale processes}

The analysis in near-real time of thermal images transmitted on board allowed crossing several eddies (Fig.5a), and seeding them with surface drifters. The 3 drifters seeded in April inside the libyan eddy $(+)$ remained trapped inside at least till early October, and their trajectories materialize

12 http://www.oceanography.ucy.ac.cy/cycofos/ 
its eastward drift, as already inferred from the thermal images (Fig. 3). The CTD transect that crossed it from the Libyan shelf to the Cretan one (Fig. $5 a)$ showed ${ }^{13}$ that the minimum of salinity (indicating the most recent/less modified AW) was found on -and limited to- its northern edge. The trajectory (Fig. 5b) of the drifter released upstream on the southern periphery of the libyan eddy $(\Delta)$ in February demonstrates how successive eddies act as paddle-wheels to transport water offshore.

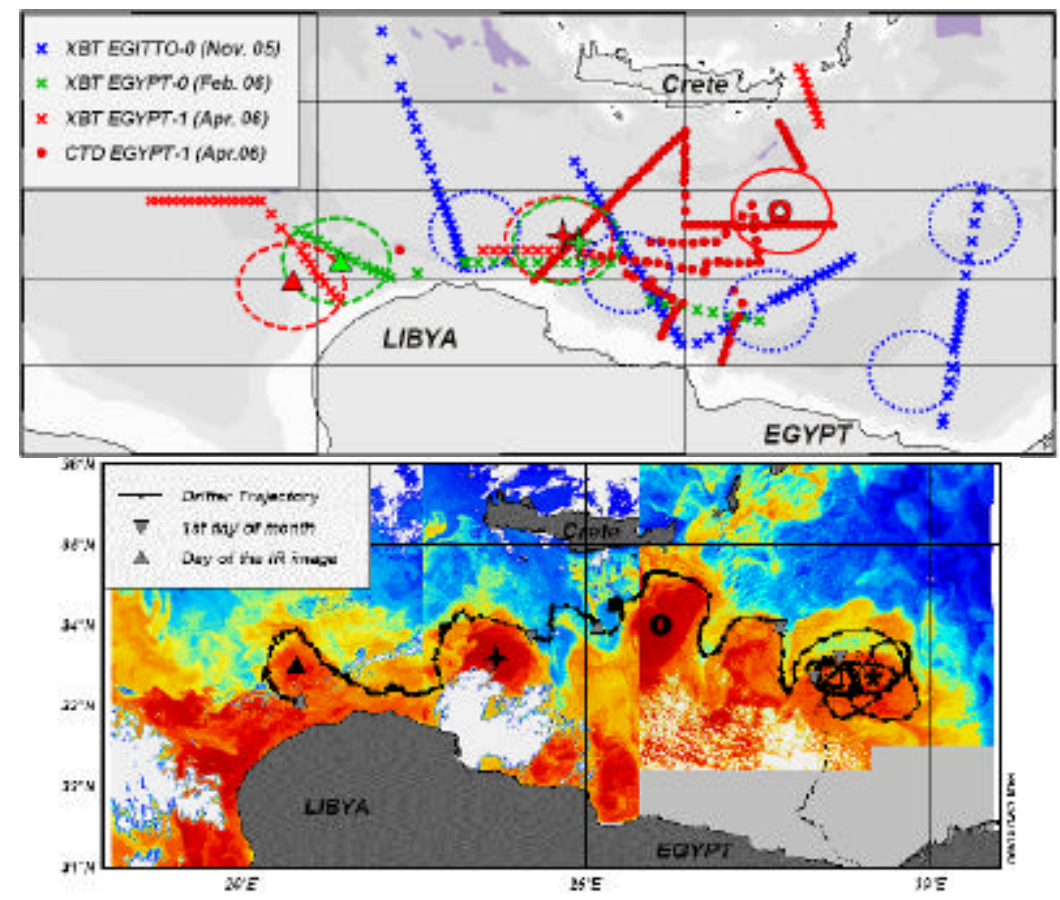

Fig. 5 a) The strategy of the EGYPT and EGITTO campaigns and positions of the eddies sampled. $b$ ) one surface drifter trajectory (from 01 February to 18 May 2006, thick line) superimposed on images from 10 February (left), 10 March (middle) and $1^{\text {st }}$ April 2006 (right). Thin line: trajectory after the loss of its drogue

\section{Discussion and conclusion}

The good correlation between in situ and satellite observations has been demonstrated again. The libyan eddy (+) has been tracked for 9 months with drifters, up to 1 year with thermal images. In February and March

\footnotetext{
${ }^{13}$ It also showed a vertical extent $>1000 \mathrm{~m}$
} 
(Fig. 3b-c) the continuity of the warmer signature from the eddy $(\Delta)$ to the eddy $(+)$ shows that AW is first flowing alongslope. Then the paddlewheel effect illustrates the mechanism of its offshore spreading, and explains why, on the CTD transect, recent AW has only been found on the northern edge of the eddy $(+)$. Although the resulting drifter trajectory (Fig. 5b) evokes a MMJ, the underlying processes are different.

Knowing the history of the mesoscale phenomena with a fine spatiotemporal interval is also important since situations looking similar can be achieved with different eddies, and since merging of eddies can be completed within few days. This also concerns other disciplines, as for instance the distribution of nutrients not only differs in and out of an eddy, but also in a one-year old eddy (as I05 in 2006) and in a newly formed one.

Provided some precautions are taken, the study of the circulation based on thermal images is efficient in the eastern basin of the Mediterranean too. However there are no constant criteria to characterise the eddies signatures, which are difficult to detect and track automatically. Such studies remain thus rather descriptive, but they are easy to carry, cheap, especially cost-efficient for in situ sampling -and indispensable for data interpretation wherever the mesoscale dynamics plays a pivotal role.

Acknowledgements. Thanks are due to HL. Fuda, R. Gerin, C. Millot, P.Poulain and G. Rougier for their contribution, to the SATMOS (CNRS/INSU/MétéoFrance) for the thermal images, and to the crews for the campaigns at sea. EGYPT received funding from the CNRS/INSU, programs PATOM/IDAO and GMMC, and Région Provence-Alpes-Côte d'Azur.

\section{References}

Fusco G, Manzella GMR, Cruzado A, Gacic M, Gasparini GP, Kovacevic V, Millot C, Tziavos C, Velasquez Z, Walne A, Zervakis V, Zodiatis G (2003) Variability of mesoscale features in the Mediterranean Sea from XBT data analysis. Ann Geophys 21:21-32

Hamad N, Millot C, Taupier-Letage I (2005) A new hypothesis about the surface circulation in the eastern basin of the Mediterranean Sea. Progr Oceanogr, 66:287-298

Hamad N, Millot C, Taupier-Letage I (2006) The surface circulation in the eastern basin of the Mediterranean Sea. Sci Mar 70(3):457-503

Marullo S, Napolitano E, Santoleri R, Manca BB, Evans R (2003) The variability of Rhodes and Ierapetra gyres studied by remote sensing observation, hydrographic data and model simulations during LIWEX (october 1994-april 1995). J Geophys Res, 108 (C9) 8119 DOI: 10.1029/2002JC001393 
Millot C, Benzohra B, Taupier-Letage I (1997) Circulation off Algeria inferred from the Mediprod-5 current meters, Deep Sea Res 44(9-10):1467-1495

Millot C (1992) Are there major differences between the largest Mediterranean Seas? A preliminary investigation. Bull Inst Oceanogr Monaco 11:3-25

Millot C, Taupier-Letage I (2005a) Circulation in the Mediterranean Sea. In: The Handbook of Environmental Chemistry, Vol.5 Part K, A Saliot ed., SpringerVerlag, Berlin Heidelberg, pp 29-66

Millot C, Taupier-Letage I (2005b) Additional evidence of LIW entrainment across the Algerian Basin by mesoscale eddies and not by a permanent westward-flowing vein. Progr Oceanogr, 66:231-250

Nardelli BB, Marullo S, Santoleri R (2005) Diurnal variations in AVHRR SST fields: a strategy for removing warm layer effects from daily images. Remote Sens of Env 95(1): 47-56

Nielsen JN (1912) Hydrography of the Mediterranean and adjacent waters. Rep Dan Oceanogr Exp Medit 1:77-192

Puillat I, Taupier-Letage I., Millot C (2002) Algerian Eddies lifetime can near 3 years. J Mar Sys 31:245-259

Pujol MJ, Larnicol G (2005) Mediterranean sea eddy kinetic energy variability from 11 years of altimetric data, J Mar Sys 58:121-142

Robinson AR, Colnaraghi M, Leslie WG, Artegiani A, Hecht A, Lazzoni E, Michelato A, Sansone E, Theocharis A, Ünlüata Ü (1991) The Eastern Mediterranean general circulation : features, structure and variability. Dyn Atm Oceans 15:215-240

Taupier-Letage I, Puillat I, Raimbault P, Millot C (2003) Biological response to mesoscale eddies in the Algerian Basin. J Geophys Res 108(C8):3245-3267

Zervakis V, Papadoniou G, Tziavos C, Lascaratos A (2003) Seasonal variability and geostrophic circulation in the Eastern Mediterranean as revealed through a repeated XBT transect. Ann Geophys 21:33-47 